\title{
BARCELONA AND ANTALYA: CARTOGRAPHIC ANALYSIS OF TWO MEDITERRANEAN CITIES
}

\author{
Antonio Millán-Gómez; Zeynep Birgonul \\ EGA1/ Universitat Politècnica de Catalunya \\ antonio.millan@upc.edu, zeynep.birgonul@estudiant.upc.edu
}

\begin{abstract}
Cartographic analysis provides a wealth of information when original sources are subjected to scrutiny with ITC tools. The cities studied here, on opposite shores of the Mediterranean, apparently different and supposedly incomparable morphologically, exhibit some akin structural traits. They interest us here, to evaluate the systems inherent to their performance.

Both cities evolved from a small nucleus and have strong geographical links and exchanges with their peripheries, and grew from from an industrial and historical background to a varied economy, in which its touristic coastline certainly shows. The tools applied, derived from Syntax techniques, as originally developed by Hillier and Hanson (1984) and their UCL colleagues, enable a revision of spatial networks qualities.
\end{abstract}

\section{Keywords}

Urban morphology, Mediterranean cities, Cartography, Urban Spatial Analysis, Space Syntax. 


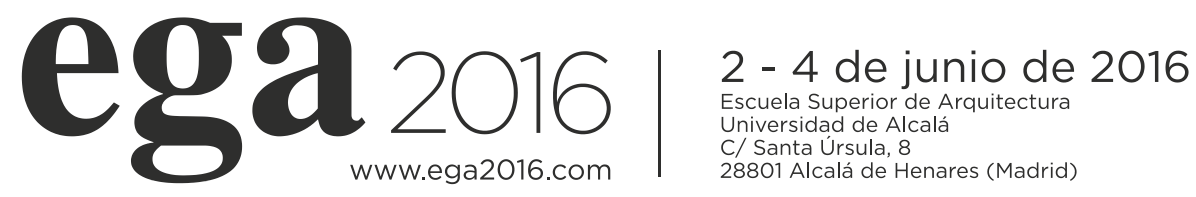

\section{Introduction}

Space Syntax techniques -originally developed by Prof. Bill Hillier \& Prof Julienne Hanson and colleagues at The Bartlett, University College London- help us in the analysis of cities and their morphologies. They matured after 1984, comparing patterns of movement, density, land use and land value, urban growth and social differentiation. For this task we use the Depthmap multi-platform software, originally developed by Alasdair Turner from University College London, and lately improved by Tasos Varoudis as Depthmap X, starting from diagrammatic Axial Maps that unveil relations in any settlement.

Both cities studied evolved from a nucleus, around which grid structures with varying densities expanded parallel to the coastline; and in both cases we find geographic and historical conditions that helped current patterns of activity.

Barcelona was pointed as the grid with highest performance (together with Santiago de Chile and Chicago) amongst 40 cities worldwide. Why? Barcelona is an open matrix of exchanges, a diversity of systems in continuous interaction. Out of the three alignments that affect the original settlement at a global, territorial or local state (i.e, the Pyrenees, the central Catalan depression and the coastal chain of mountains), the latter determines exchanges. (Millan-Gomez, Lazo Mella, \& Lopez-Moreno, 2012). The geographic setting is adequate and plain, limited by the seashore and the mountains.

As a matter of fact, this metropolis is a didactic example to examine links between spatial evolution and planning criteria. Some simulations led to comparisons between alternative morphologies to understand its three growth phases: "an emergent product of a bottom up spatial growth, which is distinguished as the organic grid of the old city. The second growth phase has been also initiated by imposing a uniform grid in a top down planning concept laid down in 1859. The building of this uniform grid called the Ensanche has taken place around the year 1891 and has been conducted in parallel to a third type of growth process. This process might be recognized as the natural growth of the suburban town centres which happened to be close to the periphery of the suggested uniform grid. The Current Spatial structure of Barcelona is a result of the intertwining between the old city, the emergent suburban growth and the pre-planned uniform grid.” (Al Sayed, Turner, \& Hanna, 2009).

At the Anatolian South coastline, a variety of interconnected cultures were the cradle of successive civilizations. Antalya is an ancient city, close to heritage pieces and built from B.C. 10 century. The area became recently a hectic tourist resort in the Turkish Republic and the Mediterranean coast, with a record of 12.5 million tourists passing through the city in 2014 (Çetingüleç, 2014), evolving from an emergent city, with industrial and agricultural roots. A rocky plateau elevated $35 \mathrm{~m}$. over sea level explains why modern traffic goes through this sector. We perceive inorganic urban formations aggregated individually among the geographic elements. The layout of the city shows how similar assemblages fuse with time, into an organic fabric. The diagram of connections is clear: strong lines at this plateau, a collection of clusters close to sea level and still inorganic, scattered settlements at the shallow core.

\section{Methodology: Syntax as Cartographic Analysis with Depthmap X}

Our work sequence is easy: we proceed from the connected areas in the network, to detect those that remain busier (integrated) over the years, linked to the through ways chosen by most people, and contrasting with the alternative routes chosen to move towards all sectors.

\section{Barcelona, Spain}

- City Center Limits:

- Surrounding Area:

- Metropolitan Area:

Antalya, Turkey

- City Center Limits: (Muratpasa): $92 \mathrm{Km}^{2}$

- Surrounding Area (Muratpasa +Konyalatı): 656,4 Km²

- Metropolitan Area:
$100 \mathrm{Km}^{2}$

(Barcelona + Badalona + Hospitalet D’Llobregat) $:$ 134,67 Km²

$803 \mathrm{Km}^{2}$ 


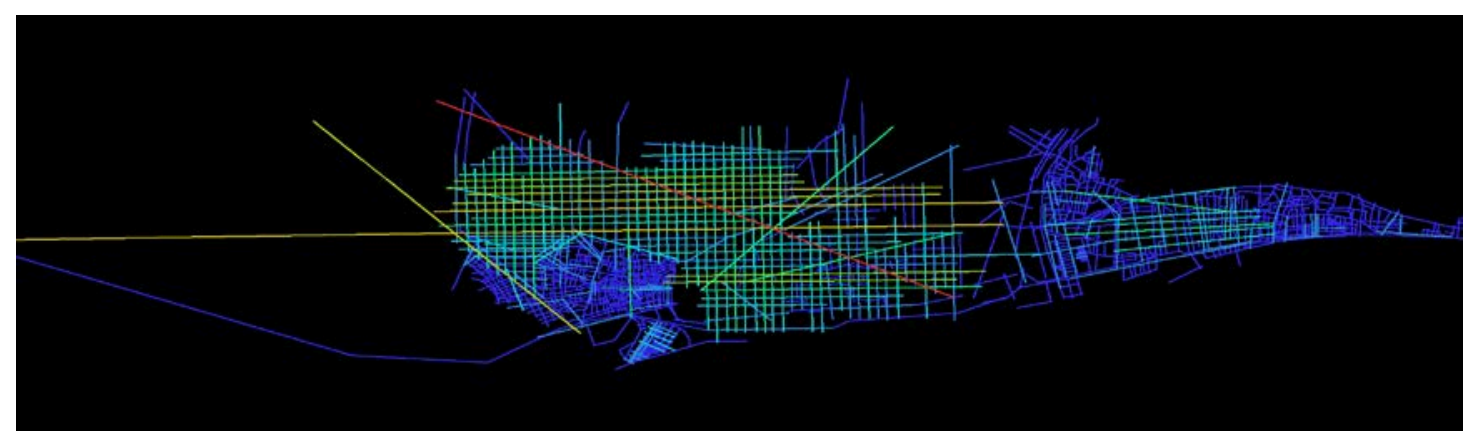

Fig. 1a. Barcelona Connectivity

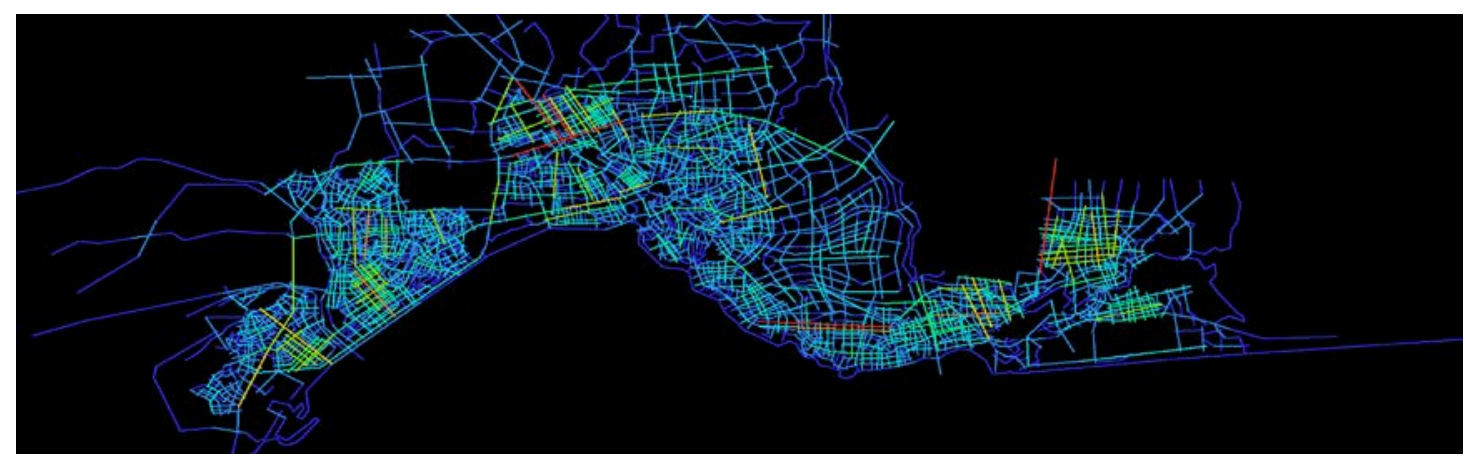

Fig. 1b. Antalya Connectivity

Settlements can be described by axial maps with "the minimal set of the longest straight lines of unobstructed movement that crosses and interconnects all open spaces in the system (Hillier and Hanson, 1984)”. Such lines constitute secondary graphs developed from standard primary graph representations. The first operation is to unveil the pattern of connectivity and their number, or node count, in these graphs (fig. 1).

Second-order measures (the intelligibility of the pattern, or correlation between connectivity and integration) and synergy between local and global scale provide information on how the different states are counterpoised.

Connectivity graphs -where hot colours (red, orange, yellow) indicate high values and cold colours (blue, green) stand for low values- are the starting point in this topological approach (Fig 1).

Circulation is channelled through Gran Via in Barcelona, its longest segment, helped by Av. Diagonal and two diagrammatical axes (Meridian and Parallel). Here you can see them complemented with the throughways in Badalona, showing a gap that invites completion.

Antalya's map is an imperfect grid, with several patterns related with dispersed urban nuclei and the main circulation lines that adjust to areas within the territory. The highly circulated roads at Antalya, 'Gazi Bulvarl' and 'Hürriyet Caddesi', are connected to each other and act as main arterial road.

Which simulation model are we following? Dichotomies (between static and dynamic, local -immediate neighbourhood- and global properties constructed with all vertices) provide a model to obtain measures for analysis, with basic notions: connectivity, integration, control and choice (TURNER, A., 2004).

The basic local static measure is connectivity: "total number of nodes at radius 1", how many other lines are only one step away from each line (i.e. immediately connected to it). The system of study reaches a critical point when density diminishes.

The "global dynamic" measure is "choice": 'how likely a location is to be passed through) on all shortest routes from all spaces to all other spaces in the system' (HILLIER ET AL, 1987). Choice may be a better predictor of movement for "inhabitants" with better knowledge of the layout than for "strangers" who rely on reading the 


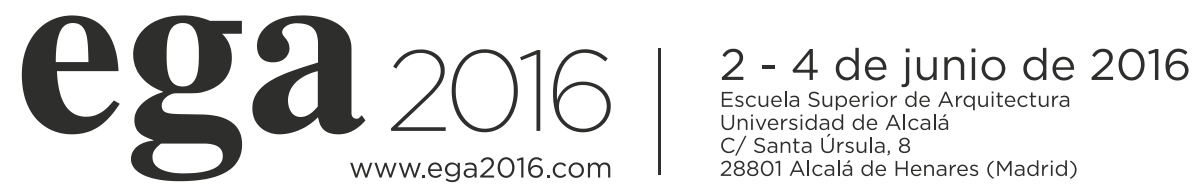

layout, in order to move around.

The global state measure is integration, that indicates how many other lines are up to $\mathrm{n}$ stops away from each line and points at graph general structural qualities (BLANCHARD, P.,VOLCHENKOV, D., 2008)-. Approached by many authors, it is "the degree to which a space is likely to lie on the shortest routes from all points to all other points in the layout is not an intuitable property of the layout, whereas the number of steps a space is from all other spaces is an intuitable property in that knowledge of it can be built up over time by moving around the layout". Integration leads to intelligibility, and intelligibility leads to a stronger "movement interface" between inhabitants and strangers"(B. HILLIER, 2002, p. 238). Segment count is the strongest component of the integration measure with restricted radius and Node count is transcendental, since it suggests activity levels and, though it may seem paradoxal, "In a significant sense, least angle or topological integration measures contain more useful metric information than their metrically weighted versions" (HILLIER, TURNER, YANG, PARK 2007). This fact leads to compare topological integration with different radius in the cities studied. A system of "urban villages" was implicated in Barcelona from its origins, with themes such a renewed paradox of centrality: having provided impetus for its growth, it has to be re-interpreted.

Second order measures in the form of Pearson product-moment correlation coefficients (r) convey added information: intelligibility (correlation of connectivity and integration) indexes the degree to which the number of immediate connections a line has are a reliable guide to the importance of that line in the system as a whole. Concerning movement, correlation between integration and choice indexes the accessibility of a space as destination from all others and the likelihood of being a shortest routes destiny from all points to all other points in the layout. It shows the agreement between a space's potential for to-movement and through-movement.

Pervasive centrality is extended over both settlements, even cores out of which each city grew, generating a shallow, permeable structure. Both cities show a nucleus and an expansion towards the coastline with dense, highly connected sectors. Line graph analysis does internalise the geometric properties of space into the graph, thus picking up "the nonlocal, or extrinsic, properties of spaces that are critical to the movement dynamics through which a city evolves its essential structures. Nonlocal properties are those that are defined by the relation of elements to all others in the system, rather than intrinsic to the element itself" (HILLIER B. 1997). Since human activity must be developed on oriented surfaces, the primary graph representing the physical network must be planar ("a graph is planar if, and only if it has a combinatorial dual” according to Whitney, as HARARY 1972, p.115 collects). Planarity affects settlements and representations, and duality must be considered in other senses: secondary graph representations are often not planar, requiring simplification and agreements with social networks.

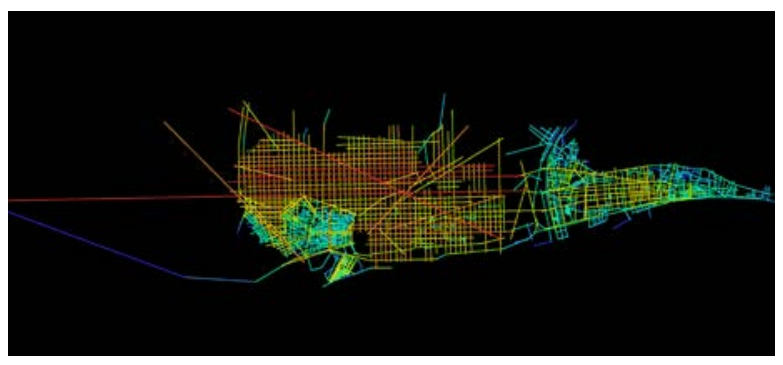

Fig. 2a. Integration [HH] R3 Barcelona

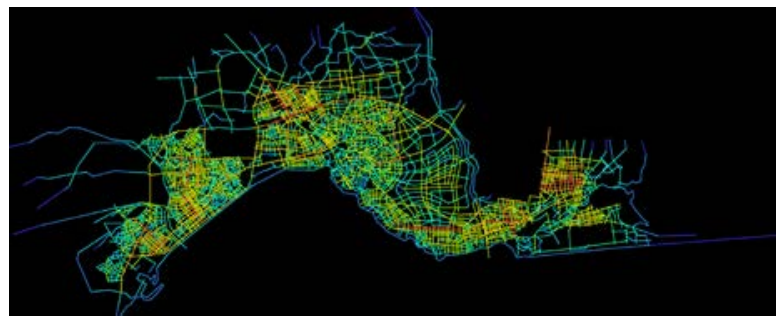

Fig. 2b. Integration [HH] R3 Antalya

In the process of this research we have perceived high similarity between integration graphs concerning integration [HH] R3 - local value-' and 'integration [HH] R1000 - global value-', in both cases. The range leading from city centres to the outskirts is highly integrated at the centre of Barcelona and more dispersed in Antalya, with the exception of the old city 'Kaleiçi'. Actually, the old city in Barcelona and the core of Antalya graph, also near the port, show counterpart measures, and a comparable historical, social, and urban metamorphosis phases.

A second point is that, since Barcelona values are high in the expansion produced from 1860 onwards, compared 
with those of Antalya, the differentiation of the local-global range is more noticeable in the latter. Owing to extensive planning, the Barcelona grid is more effective than the dispersed grids of Antalya. For that reason, the variation of values is higher for metric measures in the global graph of Antalya than in the similar case in Barcelona, inasmuch as a regular grid spreads evenly, whilst an imperfect grid concentrate integration in those areas of opportunity at the expense of the rest.

Intelligibility, measured here by means of scattergrams as correlation between global integration and local connectivity informs that the high values $\left[R^{2}\right]$ in the Eixample diminish quickly, when less connected areas -such as Badalona and the areas around the river Besós- (Barcelona $-R^{2}: 0.26835$; Antalya $-R^{2}: 0.0388641$ ). In the case of Antalya the mean depth graph shows how the seashore and touristic activities are located in clusters close to little ports and strategically close to the airport.

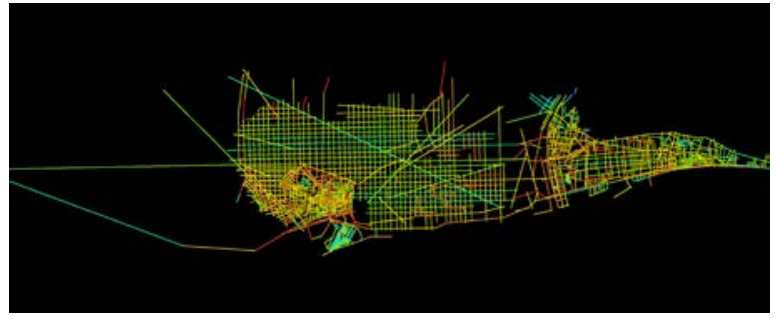

Fig. 3a. Barcelona Mean Depth [Connectivity Weight] R3

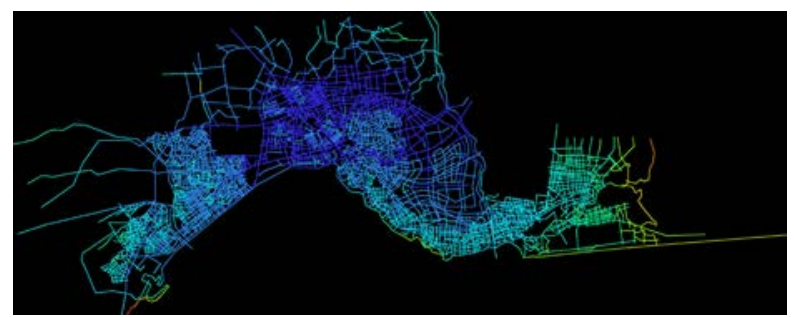

Fig. 3b. Antalya Mean Depth [Connectivity Weight] R1000

Topological and metric measures show matching values in both cities, at local and global radii, with better discrimination in topological readings (those on the left). And their (regular or irregular) grid patterns exhibit strong areas close to the sea, observing that the range between city centre in local degree has highest mean depth when compared to the global degrees; when the scale grows, depth also does it, but not mean depth, since most of the activity is located is a band near the sea. This clustering in Antalya contrasts with a straight coast line front in Barcelona, as we could already see in the connectivity graph.

Synergy values (correlation between local and global integration) are dissappointing (Barcelona $-R^{2}$ : 0.26835/ Antalya $-R^{2}$ : 0.629967). In fact one is left with the impression that a new reading, without a hurry, is required. The steepness of the line in scattergram shows a thinning of node count in Barcelona, we can see a ribbon, not a complete cloud of values, as is the case in Antalya. The different colours show sub-sectors that can be further studied, when separated and studied locally.

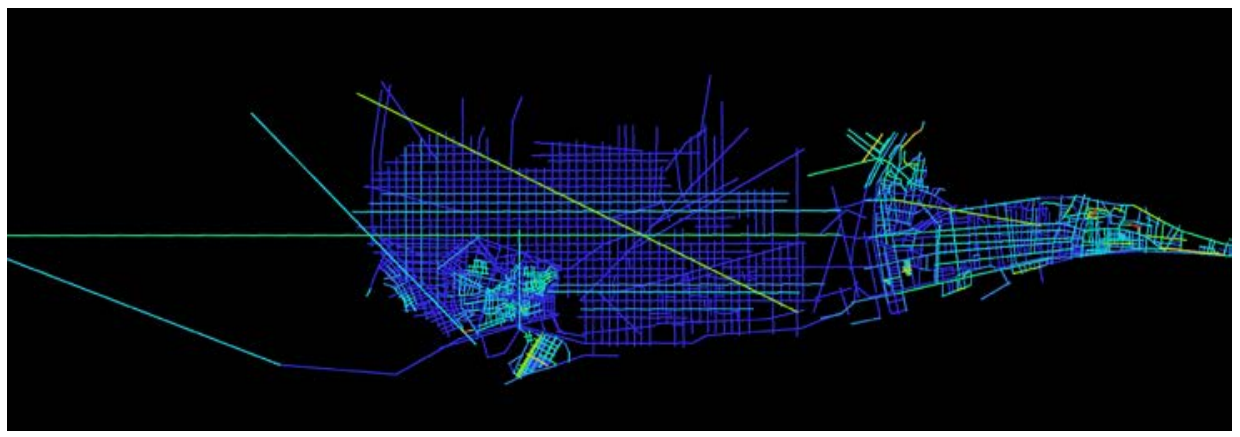

Fig. 4a. Barcelona Choice [Conn. Weight] R 3. 

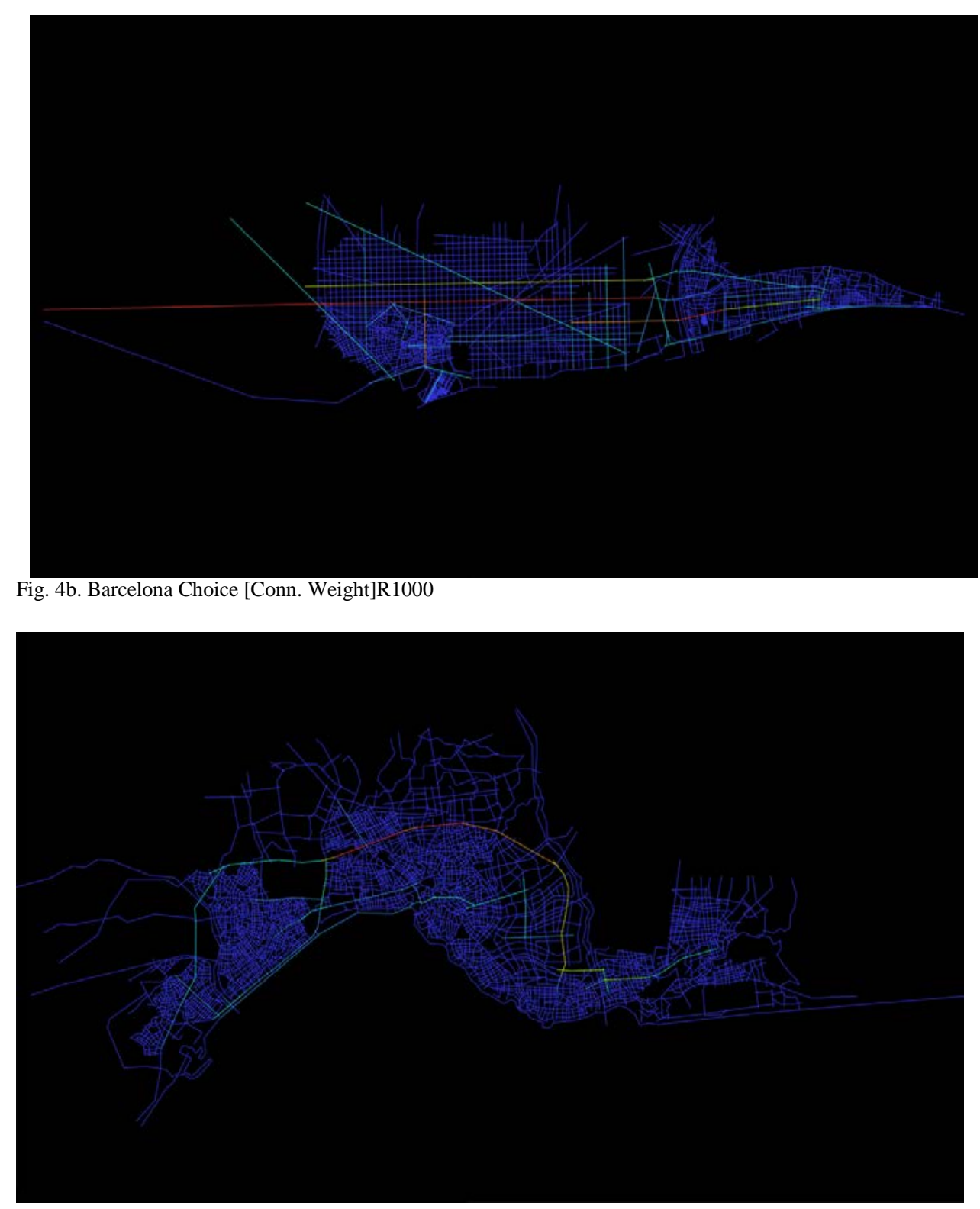

Fig. 4c. Antalya Choice [Conn. W.] R1000

Finally, a comparison of alternative routes characteristic of the movement from one location to another, unveiled through Choice, is clear in both cases (the cycle that appears in Fig 4c is a natural throughway that enables to go from the coastal sector to the upper areas in the city). The inclusion of Badalona in the metropolitan area of Barcelona clearly demands some ties between the established fabric of the city and the newly added segments. Here as in many other instances, determination is fundamental if one wants to achieve planning success.

\section{List of Figures}

Figure 1: Fig. 1a. Barcelona Connectivity / Fig. 1b. Antalya Connectivity Figure 2: Fig. 2a. Integration [HH] R3 Barcelona/ Fig. 2b. Integration [HH] R3 Antalya. 
Figure 3: Fig. 3a. Barcelona Mean Depth [Connectivity Weight] R3/ Fig. 3b. Antalya Mean Depth [Connectivity Weight] R1000 Figure 4: Fig. 4a. Barcelona Choice [Connectivity Weight] R3/ Fig. 4b. Barcelona Choice [Connectivity Weight] R1000/ Fig. 4c. Antalya Choice [Connectivity Weight] R1000

\section{Bibliography}

AJUNTAMENT DE BARCELONA. (2012). Barcelona growth: Barcelona data sheet 2012. Retrieved 2015, from Ajuntament de Barcelona: www.bcn.cat/barcelonagrowth

AL SAYED, K., TURNER, A., \& HANNA, S. (2009). Cities as Emergent Models The Morphological Logic of Manhattan and Barcelona. In L. M. Daniel Koch (Ed.), 7th International Space Syntax Symposium. Stockholm: KTH.

BLANCHARD, P., \&VOLCHENKOV, D. (2008): Intelligibility and first passage times in complex urban networks.

Proceedings of the Royal Society A. Vol. 464 no. 2096 2153-2167.

ÇETINGÜLEÇ, M. (2014, July 2014). Turkey's tourism renaissance. Retrieved October 7, 2015, from Al-Monitor:

http://www.al-monitor.com/pulse/originals/2014/07/cetingulec-turkey-tourism-revenues-arab-japanese-antalya.html\#

HARARY, F.(1972). Graph Theory. Addison Wesley

HILLIER,B.; HANSON, J., 1984: The Social Logic of Space. Cambridge University Press.

HILLIER B., BURDETT R., PEPONIS J. \& PENN A. (Hillier et al 1987): Creating Life: Or, Does Architecture determine Anything?. Architecture et Comportement/Architecture and Behaviour , 3 (3) 233 - 250

HILLIER, B.(2009). Spatial Sustainability in Cities: Organic Patterns and Sustainable Forms. Proceedings, $7^{\text {th }}$ International Space Syntax Symposium, Stockholm.

HILLIER, B. (1997): The Hidden Geometry Of Deformed Grids, or, why space syntax works when it looks as though it shouldn't. Proceedings of Space Syntax First International Symposium, London.

HILLIER, B. (2002): A theory of the city as object: or, how spatial laws mediate the social construction of urban space. Urban Design International.

HILLIER, B. (1996a). Cities as Movement Economies. Urban Design International 1: pp. 41-60.

HILLIER, B.; TURNER, A.;YANG, T.; PARK, HOON TAE (2007). Metric and Topogeometric Properties of Urban Street Networks: Some Convergences, Divergences and New Results. Proceedings of the 6th International Space Syntax Symposium. Istanbul Technical University, Cenkler.

MILLAN-GOMEZ, A., LAZO MELLA, F., \& LOPEZ-MORENO, D. (2012). Organic and Inorganic Overlapping in Old Barcelona. Space Syntax Symposium 8. Santiago de Chile: PUC.

MONTANER, C., \& NADAL, F. (2010). Aproximacions a la història de la cartografia de Barcelona. Ajuntament de Barcelona. InstitutCartogràfic de Catalunya

TURNER, A.(2004). Depthmap 4. A researcher's Handbook.

VILAR, P. (1986). Catalogne dans l'Espagne Moderne. Recerches sur les fondements économiques des structures nationales. Paris: S.E.V.P.E.N. 
Antonio Millán Gómez is Ph. D. in Architecture by UPC_BarcelonaTECH (1981) and Full Professor of Architectural Representation (1991). Senior Lecturer at ILAUD, International Laboratory of Architecture and Urban Design, directed by Giancarlo De Carlo (1985, 1986 y 1992). First Prize of the European Associaton of Architectural Education (AEEA/EAAE, 1991). He has researched on Catalan Gothic Architecture, work awarded with the Prize on Human Values in Engineering (Foundation Fecsa-Endesa/ UPC). He coordinates at present the Ph.D. Program on Heritage within the research group AR\&M/ EGAI_UPC, and participates in the International Space Syntax Symposia, contributions can be followed and the successive in UPC-Commons.

Zeynep Birgonul is architect, master IAAC and Ph. D. student at the Program on Heritage (UPV, UC, UPC) BFA Interior Architecture and Environmental Design, Bilkent University, Turkey Retail Design and Branding, Certified by DOMUS Academy, Milan

Masters of Advanced Architecture, IAAC, Barcelona

MSc. International Cooperation and Sustainable Emergency Architecture, UIC, Barcelona 